\title{
Research and Practice on the Process Cost Estimation Based on Working Procedure of Railway Transportation Equipments
}

\author{
Ziqin Ma ${ }^{1}$, Peng Lu ${ }^{1}$, Zhigang Yang ${ }^{1}$, Yongcai Sun ${ }^{1,2}$, Guangwei Qi ${ }^{1}$ \\ ${ }^{1}$ School of Mechanical Engineering, Dalian Jiaotong University, Dalian, China; ${ }^{2}$ China CNR Corporation Limited, Beijing, China. \\ Email: maziqin@djtu.edu.cn, lupeng_1983@126.com, zgyang@dl.cn, sunyongcai2010@126.com,qgw179085@yahoo.com.cn
}

Received December $16^{\text {th }}$, 2010; revised January 20 ${ }^{\text {th }}, 2011$; accepted January $24^{\text {th }}, 2011$.

\begin{abstract}
With the rapid development of Chinese economic, enterprise cost control and management of enterprise face enormous challenges. Traditional cost control and management are almost dominated by after-costing in mainland. Prior-cost estimation is generally based on statistical result of historical cost data. The theories of cost accounting and Enterprise Resource Planning are uses for reference. The prior-estimation of process-based cost of railway transportation equipments is researched and practiced from the product manufacturing process. In the view of refined management of costs, the constitution of the process cost is analyzed in manufacturing process of railway transportation equipments, and it is presented that a mathematical model of cost estimation based on working procedure. Enterprise could know the process cost of a product before it is manufactured by it. That provides a reliable basis for controlling and managing the enterprises prosecution cost. Then the process cost estimation based on working procedure of a gear is selected as an example, which is one of the gears in starting transmission of the railway locomotive diesel engine.
\end{abstract}

Keywords: Refined Management, Process Cost, Cost Estimation, Working Procedure, Railway Transportation Equipments

\section{Introduction}

Cost estimation is an important means for strengthening enterprise cost management. The reasonableness and accuracy of estimation is the key in determining their profitability, competitiveness and sustainable development. The cost estimation and control in Chinese railway transportation equipments manufacturing industry can reduce the waste of resources in labor power, material and financial and enhance their skill level even the whole manufacturing [1].

Along with the rapid development of Chinese railway transportation equipments manufacturing industry, cost estimation has become increasingly important role. The method of estimation is also developing towards the direction of more scientific and rigorous. Although the level of cost control and management has been improving, it has not break down the dominating status of post-costing. This rough costing method not only does not reflect the real resources consumption during produc- tion, but also affects measurement and reports of other managing information, so it can not meet the needs of cost management in manufacturing at this stage.

In this paper, we submit the method of the process cost estimation based on working procedure for conquering the shortcomings and limitations of cost accounting, Activity-Based Costing (ABC) and Enterprise Resource Planning (ERP) cost checking, which based on the cost checking of Chinese traditional railway transportation equipments manufacturing industry. This method can estimate the production costs in advance and guide the product manufacture cost control and management in point of engineering view. Make the process of products as the basic cell in estimating costs which forms the model of process-based cost estimation more carefully and analyze the process cost of the transmission gear in a locomotive enterprise. The relative theory and method has important reference to the cost calculation in the process of other product life cycle. 


\section{Accounting Cost Calculation}

\subsection{Accounting Cost Estimation}

There are some methods of accounting cost estimation in common use. The high-low method of cost estimation is direct way to determine the variable cost and fixed cost. Its main idea is to confirm unit variable cost to the cost variance of the highest point and the lowest point cost of volume of business history in relevant range. And fixed cost can be got by subtracting variable cost from total cost. Scatter diagram is a useful means of cost estimation using graphic method. It is more efficient especially together with the use of other methods of cost estimation. That method is to draw the historical cost data points on the coordinate diagram and to determine the cost pertinence. Least-squares regression analysis is to develop the observation data into a cost estimation formula using mathematical methods. Its idea is to minimize the sum of vertical variance between actual cost values and estimated values of each observation point [1].

Accounting prior-cost estimation is generally based on statistical result of historical cost data. It considers only the factor of the volume of business generally, and lacks of affirmatory conditions. So the estimated result is imprecise.

\subsection{Accounting Costing}

Product costing makes product as the basic cell in calculating cost, such as particular product or batch of products, or a particular manufacturing process. The costing method is called manufacturing costing method within the range of manufacturing [2].

\subsubsection{Cost Structure}

The cost structure of manufacturing cost method includes direct materials and direct labor and manufacturing overhead.

Direct materials cost is the cost of main raw materials applied to a particular product. It depends on the consumption number of unit material. And it can be identified simply by multiplying the consumption number of raw materials and its unit cost.

Direct labor cost is the cost of labor applied to a particular product. It can be got by multiplying the direct labor time and wage rate.

Manufacturing overhead includes all manufacturing cost besides direct materials and direct labor. It is used directly for production, but it fails to be credited directly to a particular product cost. Most elements of manufacturing overhead do not have direct relationship to processing of the product. In actual production costing, if the workshop produces only a product, the manufacturing costs can be reckoned directly in production cost of the product, otherwise the manufacturing cost is reckoned in various products respectively ruled by reasonable allocation method. There are a lot of methods to assign manufacturing cost. Some of them are commonly used, such as proportional distribution of the production hours, proportional distribution of worker's wage, proportional distribution of machine hours and proportional distribution of annual planning.

\subsubsection{Costing Methods}

The manufacturing costing methods can be divided into category costing method, job order costing method and process costing method [2].

The category costing method is a calculating cost method considering the assortment as cost objectives to collect and allocate production costs. The costs are distributed between finished product and good in process. This method is suitable for volume-produce of one step produce and multi-step produce calculating costs according to production steps on management.

The job order costing method is to collect production costs in accordance with the batch or order form and mainly used in single and small batch production. This method seems each product or each batch as the cost objective to calculate the costs. The calculating cycle of cost consistent with its life cycle and the production costs are collected in different batches.

The process costing method is to calculate product costs based on production steps and species of goods to collect and allocate production fees applying for continuous, large and multi-step producing industrial enterprises. In the light of different situation, it can be divided into parallel step, the proportion of law equivalent units, and gradually carried forward sub-step.

\subsubsection{Costing Process Flow}

The general costing process flow is summarized as Figure 1.

1) Identify cost objectives and cost projects. For manufacturing, the cost objectives include product category, product job order and product process.

2) Audit various expenditures and costs strictly. Determine the costs included in products.

3) Accumulate and allocate on productive expenses elements. Allocate on various costs according to projects among different products.

4) Accumulate and allocate auxiliary production costs.

5) Accumulate and allocate manufacturing overhead. For the allocation of manufacturing overhead, you should pay more attention on selecting the distributing standard.

6) Distinguish the costs between work-in-process and finished product.

7) Calculate the total cost and unit cost of finished products. 


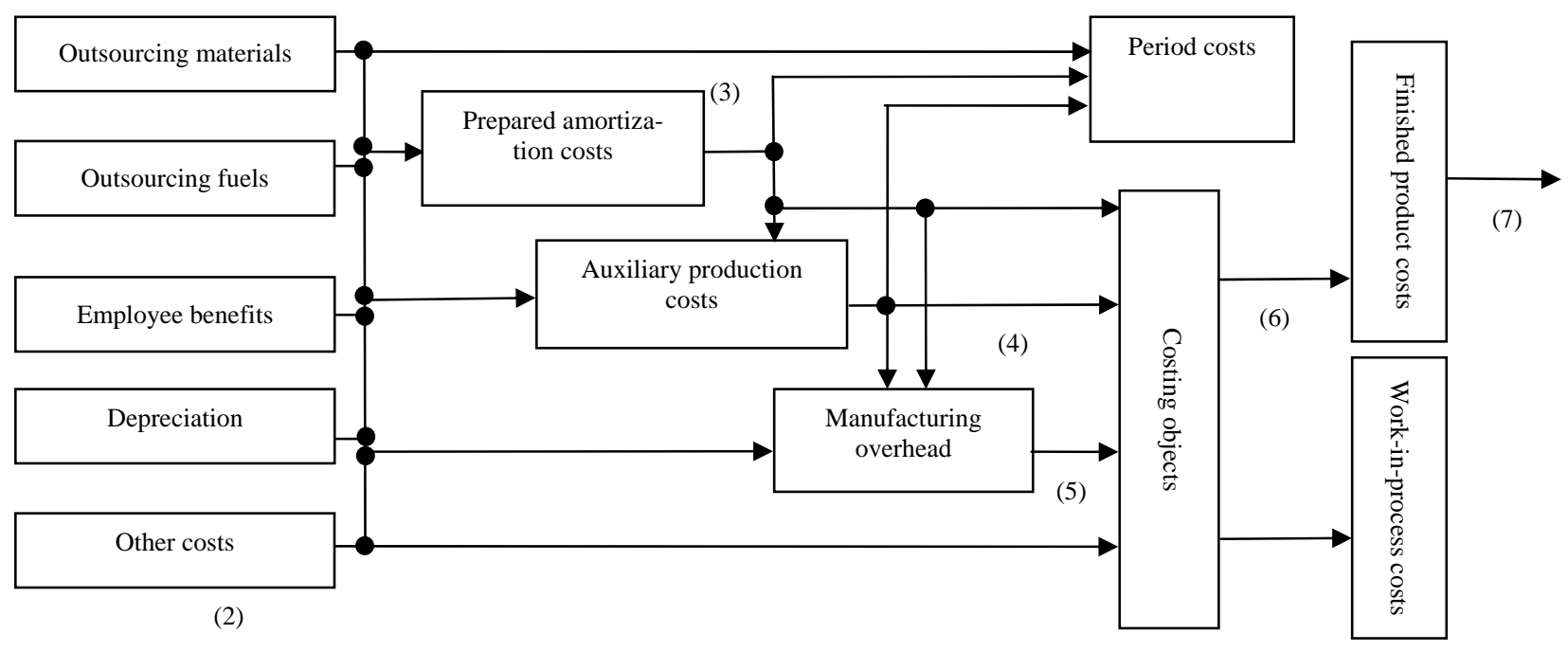

(1)

Figure 1 Product costing block diagram.

Accounting costing method is based on a total quantity, and calculate unified distributing rates of manufacturing overhead to allocate the manufacturing overhead. The main purpose is to create cost-sharing provide a unified basis. But with the increasing complexity of manufacturing costs, they can not show the causal relationship between output and costs objectively using every kind of allocation criteria, which lead to results coarse relatively. In addition, this is post-costing method, which only tells you the costs occurring in each project, cost overruns or savings, and the reason is unclear, the responsibility is unknown. So it can not control cost effectively.

\section{Activity-Based Costing}

$\mathrm{ABC}$ is a cost checking and management method, it allocates the consuming resources to activities ruled by resource driver and assigns collecting costs to cost objectives according to activity driver. Its characteristic is to calculate costs surrounding the activities. The core idea of this method is to ascribe manufacturing overhead to each activity, and then share each activity costs to product costs. The main difference between ABC and traditional method lies in the ways of allocating manufacturing overhead. ABC has its own basic concept that the manufacturing gives birth to activity, the activity consumes resources and produces costs and the product consume the activity. It assigns the manufacturing overhead to products through two stages [1], the first is to collect all consuming resources fees of job center to generate activity costs. The other stage is to distribute the collecting costs ruled by activity driver to products, and then calculate the product costs. The calculation principles of ABC are shown in Figure 2.

The calculating process of ABC:
1) Activity analysis.

2) Determine the resource driver, and then establish activity cost.

3) Confirm the activity driver and the distribution rate of each activity cost.

4) Allocate activity cost.

5) Calculate costs of each cost target, the costs content total costs and unit cost.

Based on activities, ABC assigns indirect costs using different distribution rates, which is an innovation. But in fact, the distinction of activity is difficult, the operation of setting the costs on activity is based on subjective estimated data, the accuracy of results is impacted greatly [3].

\section{ERP Costing}

Enterprise Resource Planning reflects the most advanced enterprise management theory all over the world, which unified the logistics, capital flow and information. Based on information technology, ERP integrates all resources information comprehensively using advanced management idea in modern enterprise, and ERP is a comprehensive and systematic management platform providing decision-making, planning, control and evaluation of business performance [4].

ERP cost checking supports ABC as well as traditional method of varietals method, job lot method and step allocation method, which is based on product structure, namely BOM. In calculation, the bottom is raw material. The method of calculating direct materials costs and direct labor costs of each level is convolution. The calculation of direct materials is shown in Figure 3 [4]. To calculate direct labor costs is to accumulate costs from bottom to higher level using process route file and BOM 


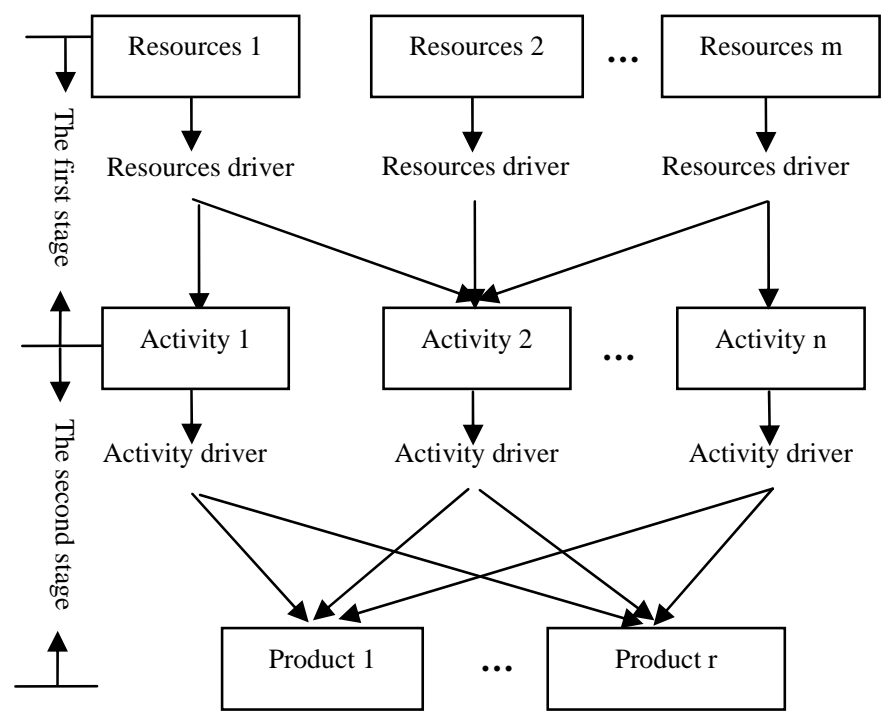

Figure 2. Calculation principle of ABC.

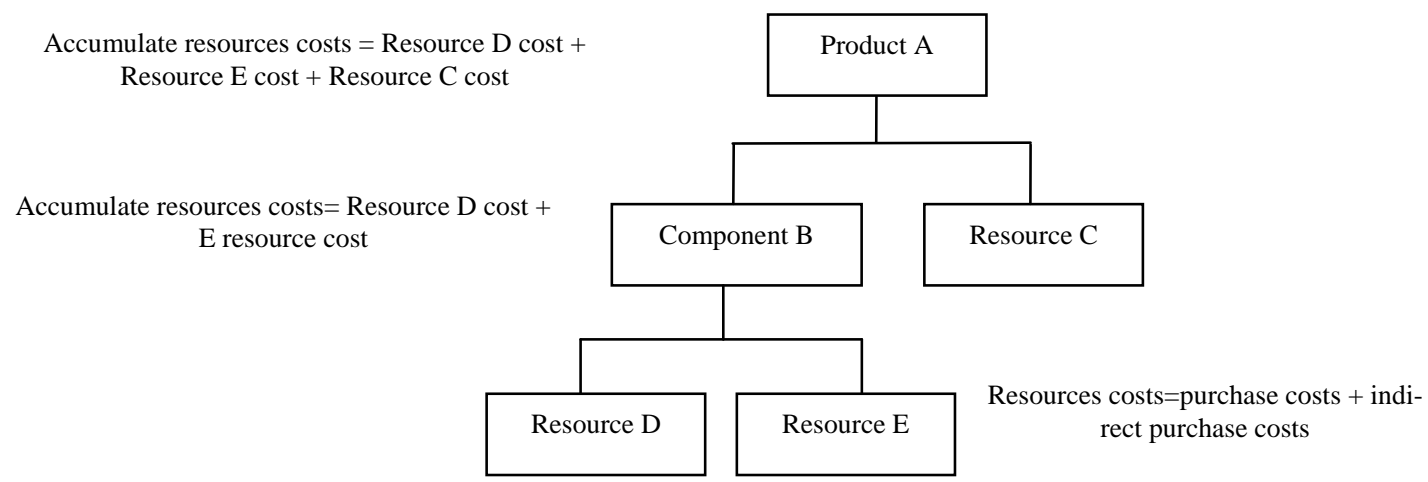

Figure 3. Direct materials costs calculation.

until to the highest level, it is shown in Figure 4 [4]. But the manufacturing overhead adopts traditional allocating method. However, with the increasing proportion of manufacturing overhead in product structure, this approach has been unable to meet the needs of decision-making.

The basic data related to ERP cost checking are displayed as follows: the numerical relationship between structure chart of products and materials in BOM, the quota of standard time and consumed materials, procurement costs recorded in item master, various time cost rates in work center file, standard time in process route file, the data of completion report and materials received report and so on.

The work of calculating product costs in ERP can be divided into the following.

1) Determine cost objectives.

2) Ascertain the period of calculating costs. It is how long between the two-time calculations.

3) Check the actual costs of materials.
4) Collect and allocate each production fees.

5) Allocate product costs between finish products and goods in process.

ERP cost management can really make enterprises achieve prior-planning, mid-event control and postanalysis to improve the management level and enhance he competitiveness. By means of ERP, enterprises can check costs more exactly and control costs more effectively.

\section{The Process Cost Estimation Based on Working Procedure}

Process cost is the monetary measure of the relevant consumption in the manufacturing process of products or components, it is one of the core component of products cost. Process cost forms in the production process. The characteristic of machining affects the method of cost. Cost accounting provides information for cost management [5].

The process cost estimation based on working proce- 


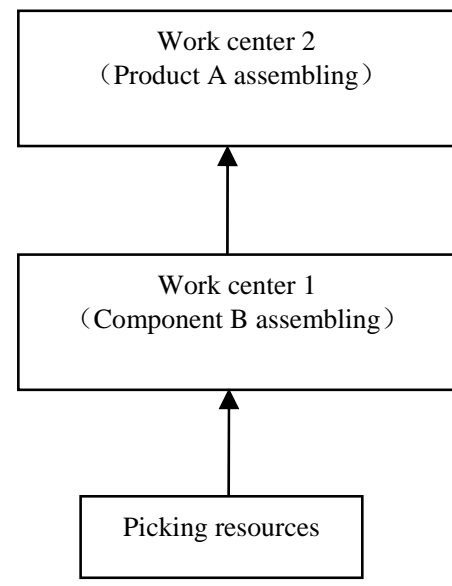

Direct labor costs 2= work center 2 rates $\times$ Product A assembling time + Direct labor costs 1

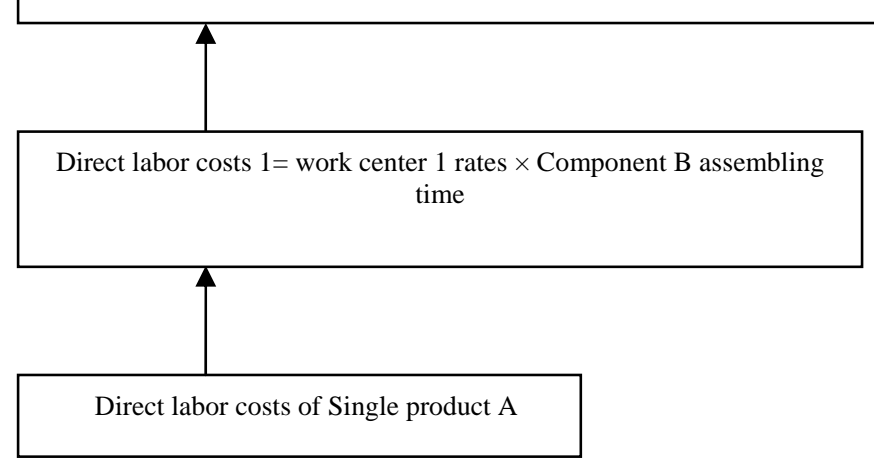

Figure 4 Direct labor costs calculation

dure replaces the method of the traditional rude cost allocation in terms of cost refined management. In terms of technology, use the method of prior estimate which could amend the results of the production process timely and direct production in turn. The method of cost estimation based on engineering in China is still in the stage of experience. In which the process cost estimation based on working procedure is the most sophisticated and relatively high accuracy. The basic data of this method comes from process cards, standard time quota and material quota, standard price, standard rates and so on. This makes the allocation of indirect costs more accurate and true and the resulting cost information more exact and detailed. Not only solve the traditional problem of irregular distribution, but also remove the subjectivity. The costs associated with the process are shown in Figure 5.

The method of calculating the process cost estimation based on working procedure is to calculate the process cost of each process according to the manufacturing process of the product or the component. In the given estimating model, all costs are related to specific process. For different costs, they are allocated to different products or components according to different rules, this method can make the model more flexible and practical. The costs include direct materials, direct labor costs and indirect costs. The sum of the all process costs based on working procedure of one part is the singleton part costs of this part, the singleton part costs of the whole product is to integrate all parts' costs in terms of the product's structure.

The process cost estimation based on working procedure can be summarized as follows [6] in Figure 6.

1) Determine the components of raw materials and manufacturing parts in direct sub-parts of the components according to the BOM of manufacturing.

2) Determine the following factors according to the process card, the procedure card, the time quota and the material quota.

a) The artificial technical level of processing, adjusting and inspecting.

b) The time quota of the time per piece, the basic time, auxiliary time and so on.

c) The quota of raw materials

d) The equipment, fixtures, cutting tools, measuring tools, etc. needed in this part.

Because of the construction of railway transportation equipments are perplexed, the production type is single unit job lot production. Considering the available use of the general and specific equipment, the formula of calculating each technology and process cost is displayed as following [6,7].

\subsection{Technology and Process Cost of Direct Material $C_{c}$}

The formula of calculating the technology and process cost of direct material is shown as the formula (1).

$$
C_{c}=C_{x} \times g_{m z} \times\left(1-K_{1} \times\left(1-K_{2}\right)\right)
$$

In the Formula (1):

$C_{c}$ is the technology and process cost of direct material, yuan.

$C_{x}$ is the material price per unit weight, yuan $/ \mathrm{kg}$.

$g_{m z}$ is the process quota of the consuming direct material based on unit product, $\mathrm{kg}$.

$K_{1}$ is the coefficient of price ratio (material price based on unit weight/waste material price based on unit weight).

$K_{2}$ is the coefficient of material utilization ((the weight of a single blank - the weight of waste material)/ the weight of a single blank).

In view of the structural features of the railway transportation equipments, the volume of a blank is much larger than that waste material, so the value of $K_{1}$ approaches zero, it can be negligible, the value of $K_{2}$ is 


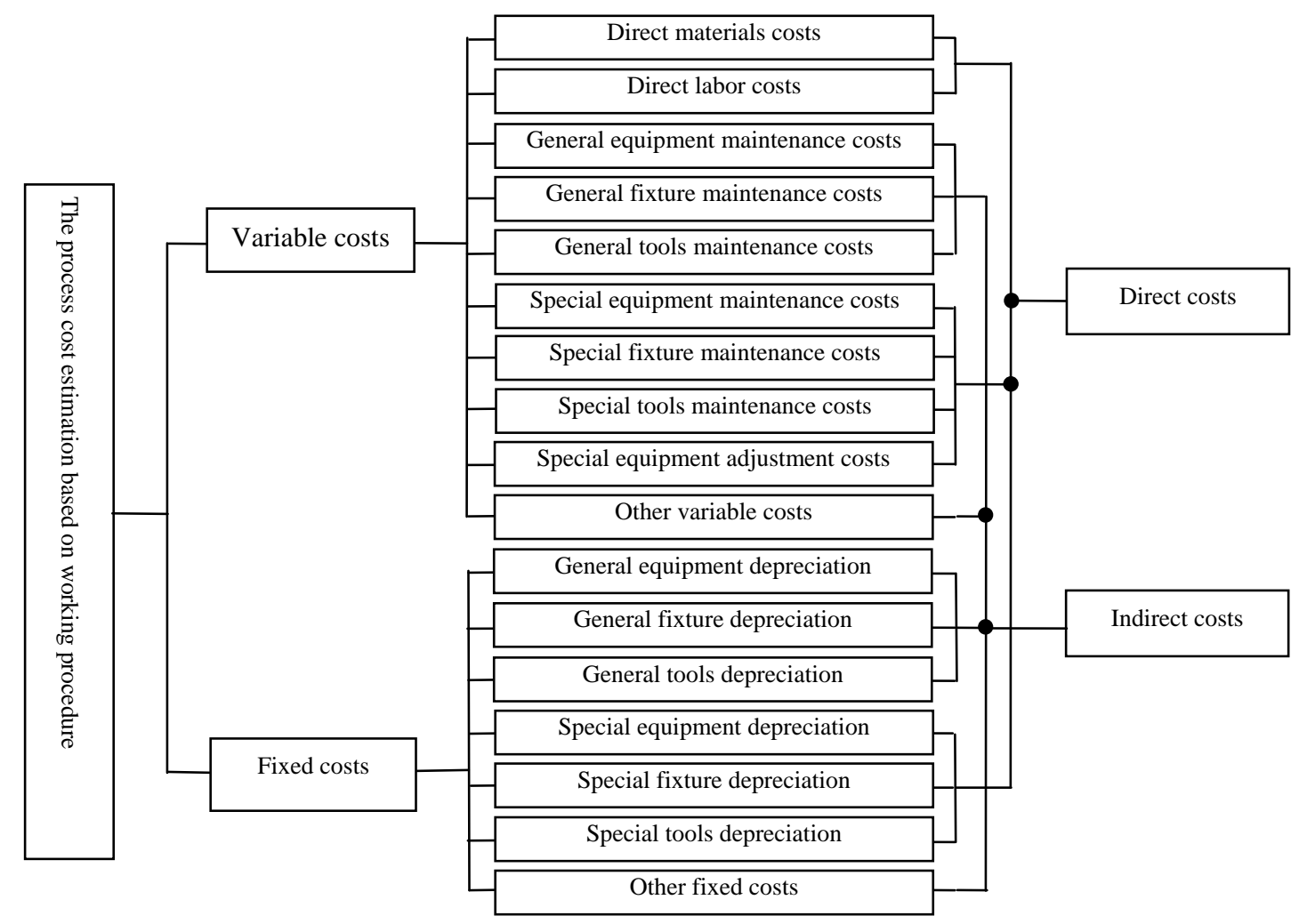

Figure 5. The process cost estimation based on working procedure constitutions.

approximately equal to 1 . We continue to simplify the Formula (1) to (2)

$$
C_{c}=C_{x} \times g_{m z}
$$

For mechanical processing, the consumption quota of raw material is composed by product and the chip which is produced by the process. The process consuming quota of bar part is shown in Formula (3):

3) Get the following data from the production, equipments, energy, finance, human resources and other departments.

a) Annual output.

b) The wage rate of artificial level.

c) The calculated unit price of raw materials.

d) Technical parameters and the depreciation of equipments.

e) Other expenses.

4) Calculate each technology and process cost, the technology and process cost of process can be obtained by adding all technology and process costs.

$$
g_{m z}=\frac{0.7854 D_{m}^{2} \gamma L_{x}}{10^{6}}
$$

In the Formula (3):

$D_{m}$ is the diameter of the blank, mm.

$\gamma$ is the density of the material, $\mathrm{g} / \mathrm{cm}^{3}$.

$L_{x}$ is the length of the consuming blank, mm.

\subsection{Process Cost of Direct Labor $C_{j g}$}

For the model of mechanical processing, machining time of a unit product as time quota is used to reflect the labor quota. The consuming quota of unit time based on unit product can be identified by Formula (4):

$$
C_{j g}=\frac{T_{d} \times C_{r g}}{60}(1+u)
$$

In the Formula (4):

$C_{j g}$ is the technology and process cost of direct labor, yuan.

$C_{r g}$ is the wage rate of workers, yuan/h.

$T_{d}$ is the consuming time of a unit part, min.

$u$ is the welfare rate related to the wage of workers, in this situation we set it as $14 \%$.

\subsection{Electricity Cost of Machine $C_{d}$}

$$
C d=\sum_{i=1}^{k}\left(\frac{P_{E} \times S_{d}}{60} \times T_{j i} \times \eta_{i}\right)
$$

In the Formula (5):

$C_{d}$ is the electricity cost of machine, yuan.

$T_{j}$ is mobile hours of one-piece, min.

$P_{E}$ is rated power of the electrical motor, kw [8].

$\eta_{i}$ is the load coefficient of the electrical motor, $\eta_{i}=$ $0.5-0.9$ [8].

$S_{d}$ is the electricity price per hour, yuan $/ \mathrm{kw} \cdot \mathrm{h}$. 


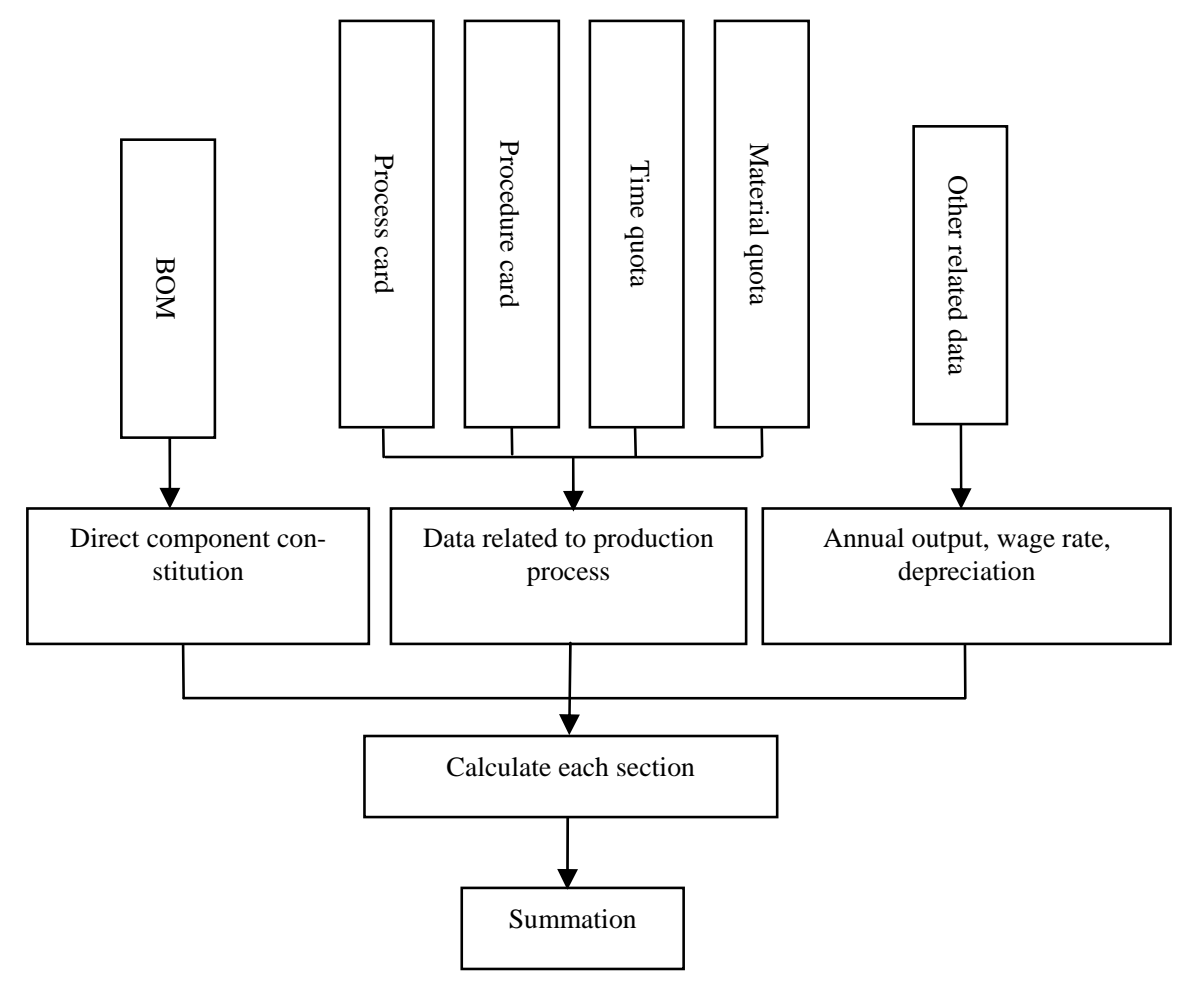

Figure 6. Process cost estimation flowchart.

\subsection{The Cost of Machine Depreciation $C$}

\subsubsection{The General Machine Depreciation $C_{z t}$}

$$
C_{z t}=\sum_{i=1}^{k} \frac{1.15 \times S_{j i} \times L_{j i}}{F_{i} \times 60 \times \eta_{z}} \times T_{d i}
$$

In the Formula (6):

$C_{z t}$ is the general machine depreciation, yuan.

$S_{j}$ is the price of machine, yuan.

$L_{j}$ is the machine depreciation rate, about $10 \%$ per year.

$F$ is the annual working time of machine, hour.

$\eta_{\mathrm{z}}$ is the utilization rate of the machine, now we chose the value as 0.95 according to the situation.

1.15 is the cost factors related to the transportation and installation of the machine.

\subsubsection{The Special Machine Depreciation $C_{z z}$}

$$
C_{z z}=1.15 \times \sum_{i=1}^{k} \frac{s_{j i}}{n_{c i} \times N}
$$

In the Formula (7):

$C_{z z}$ is the special machine depreciation, yuan.

$n_{c}$ is the depreciable life of machine (according to the table of depreciable life about fixed assets, $n_{c}$ is eighteen years).

$N$ is the annual yield.

The formula of the special machine depreciation has another format like Formula (8):

$$
C_{z z}=1.15 \times \sum_{i=1}^{k} \frac{s_{j i} \times p_{i}}{N}
$$

In the Formula (8):

$p$ is the percentage of depreciation and overhaul of special machine, $p$ is $1 / n_{c}$.

\subsection{The Cost of Adjusting Machine $C_{t a}$}

$$
C_{t g}=\frac{T_{t} \times L_{t g}}{N}(1+u)
$$

In the Formula (9):

$C_{t g}$ is the adjustment of special machine, yuan.

$L_{t g}$ is the wage rates of adjusting workers, yuan/h.

$T_{t}$ is annual adjusting hours, $h$.

\subsection{The Cost of Fixture $C_{j}$}

\subsubsection{The Cost of General Fixture $C_{j t}$}

$$
C_{j t}=\sum_{i=1}^{k} \frac{\left(s_{t j i} \times\left(a_{i} \times b_{i}\right)\right)}{F_{j i} \times 60 \times \eta_{j i}} \times T_{d i}
$$

In the Formula (10) [9]:

$C_{j t}$ is the cost of general fixture, yuan.

$s_{t j}$ is the cost of the fixture, yuan.

$a$ is the depreciated rate of the fixture, about $30 \%$ to $50 \%$ each year.

$b$ is the cost of repairing the fixture, about $10 \%$ to $20 \%$ each year.

$F_{j}$ is the annual working time of machine, hour. 
$\eta_{z}$ is the utilization rate of the fixture, now we chose the value as 0.95 according to the situation.

\subsubsection{The Cost of Special Fixture $C_{j z}$}

$$
C_{j z}=\sum_{i=1}^{k} \frac{\left(s_{z j i} \times\left(a_{i} \times b_{i}\right)\right)}{N}
$$

In the Formula (11) [9]:

$C_{j z}$ is the cost of special fixture depreciation, yuan.

$S_{z j}$ is the cost of the fixture, yuan.

\subsection{The Cost of Tools $C_{d a}$}

$$
C_{d a}=S_{d a p} \times T_{j}
$$

In the Formula (12):

$C_{d a}$ is the cost of tools, yuan.

$S_{d a p}$ is the average cost of using tools per minute while the machine is working, yuan/min.

\subsection{The Cost of Repairing Machine $C_{x}$}

The Machine maintenance costs are classified into large, medium and small repair. Medium and small amount of repair costs less. The calculation of the cost of overhaul is the same as depreciation, it is about $10 \%-15 \%$ in the general price of each machine every year, the common costs of the machine overhaul can be found in the schedule of machine overhaul fee, the period of Machine overhaul costs is three-year. $C_{x}$ is classified into 5.8.1 the cost of repairing general machine $C_{x t}$ and 5.8.2 the cost of repairing special machine $C_{x z}$.

\subsection{Technology and Process Cost of a Single Product C}

Calculate each cost above-mentioned. And the sum of them is the technology and process cost $C$ of the single part in the working procedure shown as the Formula (13). Then the set cost of all the working procedure of the single part is its technology and process cost. After all, the technology and process cost of a single product can be summed according to its bill of materials and the method of ERP (Enterprise Resource Planning).

$$
C=C_{C}+C_{j g}+C_{d}+C_{z}+C_{t g}+C_{j}+C_{d a}+C_{x}
$$

\section{The Application for Manufactured Railway Transportation Equipments}

The transmission gear in a locomotive enterprise is selected as an example, in which the fixed cost quota is determined by process. The manufacturing process and time of the gear is shown in Table 1. Table 2 is to the second process, which gives the method of process cost calculation, others to this analogizes. The entire process cost calculation of the gear is shown in Table $\mathbf{3}$.

Table 1. The manufacturing process and its processing time.

\begin{tabular}{ccccc}
\hline Process & Process Content & Process Equipment & $\begin{array}{c}\text { Mobile working } \\
\text { hours, min }\end{array}$ & $\begin{array}{c}\text { Process } \\
\text { Time, min }\end{array}$ \\
\hline 1 & Forgied material & $/$ & $/$ & 0.502 \\
2 & Rough turning & Lathe C630 & 9.251 & 10.461 \\
3 & Finish turning & Lathe CW6163C & 9.923 & 11.844 \\
4 & Hobbing & Gear hobbing machine & 91.140 & 93.471 \\
5 & Grinding side & Surface-grinding machine & 13.037 & 15.011 \\
6 & surface & M7150A & 16.550 & 20.338 \\
7 & Grinding hole & Internal grinder M2120 & 75.183 \\
8 & Gear grinding & Gear grinding machine & 72.500 & 0.500 \\
\hline
\end{tabular}

Table 2. The process costing of the second process.

\begin{tabular}{ccc}
\hline Items code & Items of Process Costing & $\begin{array}{c}\text { The Cost of Single } \\
\text { Process }\end{array}$ \\
\hline 5.1 & Direct materials cost $C_{c}$ & 54.02983 \\
5.2 & Direct labor cost $C_{j g}$ & 1.9874 \\
5.3 & Machine electricity cost $C_{d}$ & 0.56138 \\
5.4 .1 & General machine depreciation $C_{z t}$ & 0.43104 \\
5.5 & Adjusting machine cost $C_{t g}$ & 0.0114 \\
5.6 .1 & General fixture cost $C_{j t}$ & 0.00078 \\
5.7 & Tools cost $C_{d a}$ & 0.25715 \\
5.8 .1 & General machine repairing cost $C_{x t}$ & 0.14368 \\
5.9 & Aggregation $C$ & 57.42266 \\
\hline
\end{tabular}


Table 3. The entire process cost calculation.

\begin{tabular}{|c|c|c|c|c|c|c|c|c|c|}
\hline Code & Process & 1 & 2 & 3 & 4 & 5 & 6 & 7 & 8 \\
\hline 5.1 & $\begin{array}{l}\text { Direct materials } \\
\text { cost } C_{c}\end{array}$ & 53.93483 & 54.02983 & 57.42266 & 61.52007 & 85.45805 & 93.73094 & 99.90157 & 152.42656 \\
\hline 5.2 & $\begin{array}{l}\text { Direct labor cost } \\
\qquad C_{j g}\end{array}$ & 0.095 & 1.9874 & 2.2496 & 17.7593 & 2.85 & 3.8627 & 14.2842 & 0.095 \\
\hline 5.3 & $\begin{array}{c}\text { Machine } \\
\text { electricity cost } \\
C_{d}\end{array}$ & / & 0.56138 & 0.77912 & 3.5775 & 2.51192 & 0.44904 & 36.2355 & / \\
\hline 5.4 .1 & $\begin{array}{l}\text { General machine } \\
\text { depreciation } C_{z t}\end{array}$ & / & 0.43104 & 0.58548 & / & 1.85436 & 1.05558 & / & / \\
\hline 5.4 .2 & $\begin{array}{l}\text { Special machine } \\
\text { depreciation } C_{z z}\end{array}$ & / & / & / & 1.27778 & / & / & 0.99667 & / \\
\hline 5.5 & $\begin{array}{c}\text { Adjusting } \\
\text { machine cost } C_{t g}\end{array}$ & / & 0.0114 & 0.0114 & 0.0114 & 0.0114 & 0.0114 & 0.0114 & / \\
\hline 5.6 .1 & $\begin{array}{l}\text { General fixture } \\
\quad \operatorname{cost} C_{j t}\end{array}$ & / & 0.00078 & 0.00088 & / & 0.00232 & 0.00314 & / & / \\
\hline 5.6 .2 & $\begin{array}{l}\text { Special fixture } \\
{ }^{\operatorname{cost}} C_{j z}\end{array}$ & / & / & / & 0.0024 & / & / & 0.003 & / \\
\hline 5.7 & Tools cost $C_{d a}$ & I & 0.25715 & 0.27578 & 0.88367 & 0.42478 & 0.4369 & 0.662 & / \\
\hline 5.8 .1 & $\begin{array}{c}\text { General machine } \\
\text { repairing cost } \\
C_{x t}\end{array}$ & / & 0.14368 & 0.19516 & / & 0.61812 & 0.35186 & / & / \\
\hline 5.8 .2 & $\begin{array}{l}\text { Special machine } \\
\text { repairing cost } \\
C_{x z}\end{array}$ & I & / & / & 0.42593 & / & / & 0.33222 & / \\
\hline 5.9 & Aggregation $C$ & 54.02983 & 57.42266 & 61.52007 & 85.45805 & 93.73094 & 99.90157 & 152.42656 & 152.5216 \\
\hline
\end{tabular}

By the calculation above, the estimated cost for the transmission gear is 153 yuan, the results of this method is accurate and reliable, and the calculation is straightforward, easy to grasp, and has a strong practical value.

\section{Conclusions}

The process cost estimation based on working procedure is playing an increasingly important role in Chinese modern railway transportation equipments manufacturing industry, the reason why it is called estimation is because the basic data of it are estimated. Compared with the traditional cost checking methods, the quantitative estimation for process cost can provide the product planning and design more scientifically, accurately and quickly, when the product being tendered or discussed. The quantitative estimation for process cost during process planning stage can find the key of the best balance between product performance and cost quickly.

In this paper, we discuss the basic theories and process for cost checking and estimate the process cost of a single product which based on the transmission gear in a locomotive enterprise process. The method of the process cost estimation based on working procedure is based on the technology information during the process of manufacturing cost, which is an advantage. It is more accurate and reliable than other forms of cost assessment, but needs detailed and accurate information on working procedure cost before the calculation. The works on the process cost estimation are gradually developing in Chinese enterprises and need further study and make process cost estimation practical, systematization and standardization. More importantly, establish the system of process cost estimation.

1) Set up standard basic database. The integrity, consistency and reliability of basic data affect the results of process cost estimation directly.

2) Achieve generalized process cost estimation. Manufacturing overhead calculation of process cost estimation and cost accounting describe manufacturing costs from different angles. Manufacturing overhead calculation of cost accounting has formed a standard. Therefore, process cost estimation should be closer to manufacturing overhead of cost accounting and achieve generalized process cost estimation. 
3) Achieve process cost estimation under different conditions. Require different process cost estimation models and methods in different known conditions, applications, value of parts and so on.

4) Guide product design and process planning with target process cost. Target process cost is the core of business target cost. It must limit the product structure, materials and process methods in order to make process cost lower than target process cost.

5) The prior planning, mid-control and examination behind of process cost.

6) Achieve digital process cost estimation. Computerized process cost estimation can reduce the intensity of labor and enhance the efficiency and accuracy of process cost estimation.

The process cost estimation based on working procedure of railway transportation equipments is an application of the proposed process cost estimation framework, which varies by company and needs continuous improvement in the application. It is not far from what this paper title implies with advanced enterprise management theory, contemporary information technology and so on.

\section{REFERENCES}

[1] J. M. Wayne, R. D. James and A. L. Hartgraves.
"Management Accounting," Shanghai University of Finance \& Economics Press, Shanghai, 2005.

[2] Y. Q. Ou and S. X. Yang, "Cost Accounting," Capital University of Economics and Busniss Press, Beijing, 2003.

[3] C. T. Horngren, G. Foster and S. M. Datar, "Cost Accounting," Dongbei University of Finance \& Economics Press, Dalian, 2000.

[4] H. Luo, "ERP Principles, Design and Implementation," Publishing House of Electronics Industry, 2009.

[5] X. L. Wang, "Modern Process Management Technology," China Railway Publishing House, Beijing, 2004.

[6] Z. Q. Ma, "Research on Contemporary Technology and Process Management and Key Techniques,” Dalin jiaotong univercity, 2008.

[7] Z. Q. Ma, Y. Yang and Z. G. Yang, "Research on Procedure-Based Technologyand Process Cost Assessment," IEEE: The 4th International Conference on Management and Service Science (MASS 2010), No. 22402, August 2010.

[8] Y. X. Yin, "Metal Cutting Machine Manual," National Defence Industrial Press, 1964.

[9] Z. X. Luo, L. P. Zhou and Y. D. Cheng, "Metal Cutting Machine Manual,” Chongqing University Press, Chongqing, 1997. 